\title{
Food Factors and Oxidative DNA Damage / DNA Repair Systems
}

\author{
Takeshi Hirano ${ }^{1}$ and Kazuyoshi Tamae ${ }^{2}$ \\ ${ }^{1}$ Department of Life and Environment Engineering, Faculty of Environmental \\ Engineering, The University of Kitakyushu, \\ 2Division of Teacher Training, Faculty of Education and Culture, University of Miyazaki,
}

Japan

\section{Introduction}

8-Oxoguanine (7, 8-dihydro-8-oxoguanine, abbreviated as 8-oxo-Gua), a form of oxidized guanine, is a mutagenic lesion formed spontaneously in the genomic DNA of aerobic organisms (Fig. 1) and by the actions of exogenous factors, such as ionizing radiation, chemical pollutants, heavy metals, food factors, and bacteria. 8-Oxo-Gua induces GC-to-TA transversion type point mutations [1]. Point mutations generated via oxidative DNA damage are involved in cancer development, because mutations are a common feature of human cancers. Therefore, 8-oxo-Gua is considered to be involved in carcinogenesis. In this context, studies of 8-oxo-Gua have significant implications for understanding the underlying mechanisms of mutation-associated diseases, including cancer [2]. Although 8oxo-Gua is not necessarily the most abundant form of oxidative DNA damage, it has been the most extensively studied, because it is quite easily measured by a method utilizing HPLC coupled with electrochemical detection in laboratories $[3,4]$. The presence of 8-oxoGua and 8-oxoadenine (8-oxo-Ade) in mutagenic oxidized DNA products has been extensively studied, and their frequencies of generation in mammalian DNA and degrees of mutagenicity are similar [5-8]. The relative focus-forming activity, which indicates the mutation inducibility, of 8-oxo-Gua and 8 -oxo-Ade were reportedly $\sim 1 \%[7,8]$.<smiles>Cn1cnc2c3c(=O)[nH]c(=O)nc-3nc-2n1C</smiles>

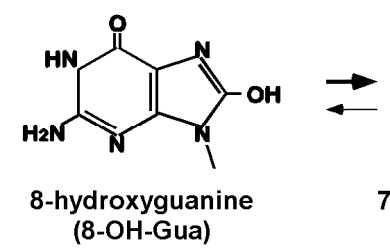<smiles>Cn1c(=O)[nH]c2c(=O)[nH]c(N)nc21</smiles>

7, 8-dihydro-8-oxoguanine (8-oxo-Gua)

Fig. 1. Structure of 7, 8-dihydro-8-oxoguanine or 8-hydroxyguanine (8-OH-Gua). 8-Oxo-Gua is formed by hydroxylation of guanine at the C-8 position.

Extensive efforts have been made to clone the repair enzymes for 8-oxo-Gua. The first information was obtained from the studies of an enzyme, formamidopyrimidine DNA glycosylase (Fpg or MutM), which excises 8-oxo-Gua, 2, 6-diamino-4-hydroxy-5formamidopyrimidine (FapyGua), and 4, 6-diamino-5-formamidopyrimidine (FapyAde) 
from the DNA of Escherichia coli [9]. This enzyme has an activity to process the resulting abasic (AP) site, by cleaving both the $3^{\prime}$ - and $5^{\prime}$-phosphodiester bonds by successive $\beta$ - and ס-eliminations [10-12]. In 1996, an Fpg homologue was identified in Saccharomyces cerevisiae $[13,14]$. This was the first report of an 8-oxoguanine DNA glycosylase 1 (OGG1). In the following year, mammalian (human and other mammals) homologues of OGG1 were identified and cloned [15-21]. 8-Oxo-Gua is efficiently removed from DNA via the shortpatch base excision repair (BER) pathway initiated by OGG1.

Among the environmental factors that are related to human diseases, food factors have a large influence on human health. To understand the mechanisms of food-related carcinogenesis, the roles of 8-oxo-Gua have been investigated in relationship with food factors. In this review article, we will focus on and describe the relationship between food factors and 8-oxo-Gua / 8-oxo-Gua repair systems.

\section{Aminoazo dyes and 8-oxo-Gua / OGG1}

Food factors have been extensively investigated in association with oxidative DNA damage and its repair systems. Some food factors, such as aminoazo dyes, are known inhibitors of OGG1 expression. Aminoazo dyes were previously used as artificial color additives to food. Some of them, such as $N$-methyl-4-aminoazobenzene, $N, N$-dimethyl-4-aminoazobenzene, and 3'-methyl-4-dimethylaminoazobenzene (3'-MeDAB), are hepato-carcinogenic. We previously analyzed the effects of $3^{\prime}-\mathrm{MeDAB}$ on 8-oxo-Gua repair systems in rodent livers, and reported that 3 -MeDAB increased 8-oxo-Gua generation and decreased OGG1 expression, possibly by cleaving the protein [22]. These results suggested that the liver carcinogenicity of $3^{\prime}$-MeDAB was due to an increase in 8-oxo-Gua generation via 3'-MeDABinduced downregulation of OGG1 expression.

The use of $3^{\prime}$-MeDAB as a food additive is now prohibited. However, other types of azo dyes are still being used. Therefore, more research is needed to define the effects of azo dyes on human health.

\section{Alcohol and 8-oxo-Gua / OGG1}

Alcohol consumption has been associated with a variety of human cancers for several centuries. Recent studies revealed that alcohol consumption is associated with an increase in breast cancer incidence in women [23, 24], esophageal cancer [25], and colorectal cancer [26, 27]. On the other hand, the cancer-preventive effects of alcohol drinking have also been reported. It is well known that moderate consumption of wine may prevent some types of cancers [28-30]. These studies concerning wine consumption suggested that anti-oxidant agents, such as polyphenols, including catekin, quercetin and resveratrol, contributed to the cancer-preventive effect of wine [31]. Thus, anti-oxidant agents seem to play a key role in the beneficial effects of wine. It was also suggested that resveratrol could reduce the localized estrogen production that plays a crucial role in the development of breast cancer [32]. On the other hand, for alcoholic beverages other than wine, a cohort study suggested that alcohol (spirits and beer) consumption was associated with a decrease in the risk of renal cell carcinoma in male smokers [33]. A matched case-control study reported a similar result, in which regular, moderate alcohol (beer, wine, and spirits) consumption was associated with a decreased probability of leukoplakia occurrence, with respect to occasional or no alcohol consumption [34]. These results are not conclusive, but suggest that other 
components of alcoholic beverages (including wine) besides polyphenols may be responsible for the beneficial effects on human health.

The evidence that not only wine but also spirits and beer have cancer-preventive effects prompted us to investigate the molecular mechanisms of these effects of alcohol consumption due to factors other than polyphenols. In fact, recent evidences have suggested that the protective effects of red wine on cancer or cardiovascular diseases were not a consequence of the anti-oxidant capacity of alcohol $[35,36]$. Arendt et al. reported the reduction of DNA damage as another mechanism of the cancer-preventive function of wine [35].

In this context, we analyzed the 8-oxo-Gua accumulation level in DNA and its repair ability (8-oxo-Gua nicking activity and mouse OGG1 (mOGG1) expression) in the livers of mice treated with 3'-MeDAB, a well known hepato-carcinogen as described above, and / or ethanol, to examine the effects of alcohol consumption on carcinogenesis (Fig. 2A) [37]. The method used to determine the 8-oxo-Gua nicking activity was described elsewhere [38]. In the study, we found that $12 \%$ ethanol reduced the 3'-MeDAB-induced 8-oxo-Gua accumulation (Fig. 2B). Moreover, the 8-oxo-Gua repair activity showed a decreasing tendency in 3'-MeDAB-treated mouse livers with $12 \%$ ethanol administration, without any significant differences (Fig. 2C). The decrease in the 8-oxo-Gua repair activity seems to be a reasonable consequence of the lower 8-oxo-Gua levels. Since we speculated that OGG1 fragmentation was a key event for 3'-MeDAB-induced 8-oxo-Gua accumulation [22], we predicted that OGG1 fragmentation might be inhibited by ethanol intake, as in the inhibition of the increase in 8-oxo-Gua levels. However, $12 \%$ ethanol intake failed to inhibit the 3'MeDAB-induced fragmentation of OGG1 (groups D, E, and F in Fig. 2D). The observations indicated that ethanol intake reduced 8-oxo-Gua accumulation, without affecting the function of OGG1. However, since other enzymes besides OGG1 can reportedly repair 8oxo-Gua [39], we speculate that ethanol consumption might induce these 8-oxo-Gua repair systems to reduce the 8-oxo-Gua level.

\section{Coffee and 8-oxo-Gua / OGG1}

Coffee has been a quite popular beverage in many parts of the world for a long time. However, its effects on human health are not well understood. Some studies suggested that coffee consumption had preventive properties for metabolic diseases, such as type 2 diabetes [40,41], or cancers, such as hepatocellular carcinoma [42, 43] and colorectal cancer [44, 45], through its content of potentially antimutagenic substances [46]. These findings led to the hypothesis that coffee consumption lowers the risk of some types of cancers.

On the other hand, some studies provided negative conclusions for the effects of coffee consumption on human health. A large cohort study in Sweden and Japan indicated that coffee consumption was not associated with the risk of colorectal cancer [47, 48]. Furthermore, another cohort study indicated that coffee consumption increased the risk of certain cancers, such as gastric cancer [49]. These carcinogenic actions of coffee were supported by evidence that coffee contained numerous substances, such as glyoxal, methylglyoxal, ethylglyoxal, propylglyoxal, diacetyl, and acetol, with potentially genotoxic and mutagenic properties [46, 49-51]. Although the polyphenols in beverages, such as green tea, black tea, and coffee, are antioxidant substances, a recent study indicated the production of hydrogen peroxide, a harmful molecule for living organisms, by polyphenol-rich beverages [52]. Therefore, although numerous studies have been performed, the effects of coffee consumption on human health have remained undefined. 


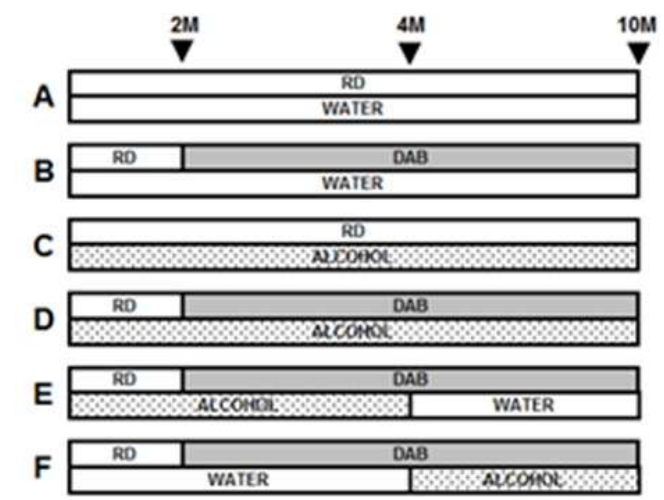

A

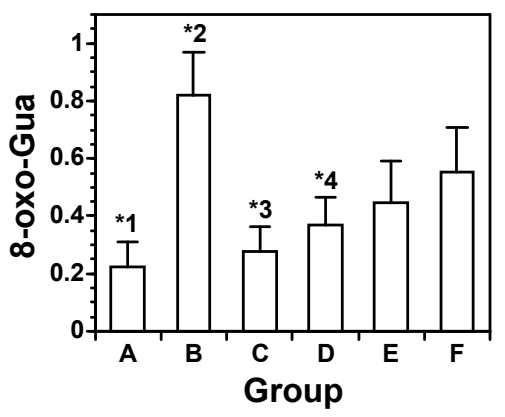

B

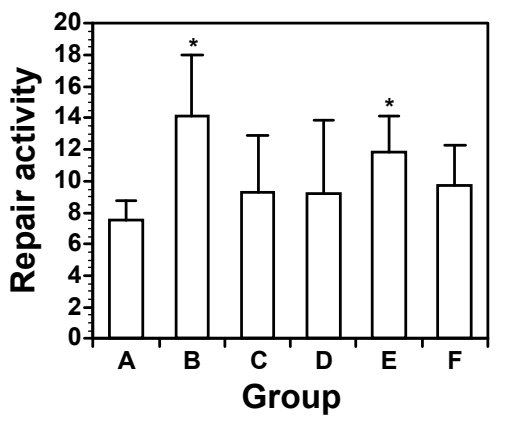

C

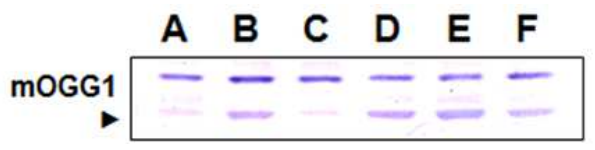

D

Fig. 2. (A) The experimental protocol. A: control [ND / water] for 10 months; B: [ND / water] for the first 2 months and [0.06\% 3'-MeDAB / water] for the last 8 months; C: [ND / alcohol] for 10 months; D: [ND / alcohol] for the first 2 months and [0.06\% 3'-MeDAB / alcohol] for the last 8 months; E: [ND / alcohol] for the first 2 months, [0.06\% 3'-MeDAB / alcohol] for the next 4 months, and [0.06\% 3'-MeDAB / water] for the last 4 months; F: [ND / water] for the first 2 months, [3'-MeDAB / water] for the next 4 months, and [3'-MeDAB / alcohol] for the last 4 months. ND: normal diet, DAB: 3'-MeDAB. (B) The levels of 8-oxo-Gua in the DNA of mouse livers. The 8-oxo-Gua value is expressed as the number of 8-oxo-dG per $10^{5}$ deoxyguanosine. ${ }^{*} 1$ : $P<0.0005$ vs. group $\mathrm{B}, P<0.05$ vs. group $\mathrm{E}, P<0.01$ vs. group $\mathrm{F} ;{ }^{*} 2: P<0.0001$ vs. group $\mathrm{C}$, $P<0.005$ vs. group $\mathrm{D}, P<0.01$ vs. group $\mathrm{E}, P<0.05$ vs. group $\mathrm{F} ;{ }^{*} 3: P<0.05$ vs. group $\mathrm{E}, P<$ 0.005 vs. group $F$; ${ }^{*} 4: P<0.05$ vs. group $F$. (C) 8 -Oxo-Gua nicking activity in the mouse livers. The activity was calculated as the ratio of the excised fragment intensity to the total substrate (unexcised substrate intensity plus excised fragment intensity). *: $P<0.005$ vs. group A. (D) Western blotting of mOGG1 protein in the mouse livers. Mouse livers were removed and homogenized to produce crude extracts. The extracts were electrophoresed and blotted onto a PVDF membrane. A western blot analysis was performed using an anti-mouse OGG1 antibody. The arrowhead indicates fragmented mOGG1. mOGG1: mouse OGG1. This figure was published in reference [37], Copyright Elsevier (license\#: 2633951132321). 
To address this issue, we focused on the effects of instant coffee consumption on the generation of 8-oxo-Gua. In our previous work, we analyzed the 8-oxo-Gua level and the 8oxo-Gua repair system in the livers of mice fed with / without a $0.1 \%$ instant coffee solution. In addition, we employed an autoclaved diet (low vitamin diet; LV diet) to maintain half of the mice under low vitamin conditions. We found that instant coffee consumption does not alter the 8-oxo-Gua generation level and OGG1 mRNA expression, although it prevents lowvitamin diet-induced 8-oxo-Gua production [53] (Fig. 3). Our study suggested that daily instant coffee consumption may provide more beneficial effects than detrimental effects. However, we have not examined other types of DNA damage. To clarify the role of coffee consumption on human health, further studies should be performed.

\section{Urinary 8-oxo-Gua level and food consumption}

Urinary 8-oxo-Gua levels are often analyzed, especially as a marker of oxidation [54, 55]. Among the urinary biomarkers of oxidative stresses, 8-oxo-Gua is possibly the most studied. We previously investigated the effects of age, smoking, dietary factors, and other life style factors on urinary 8-oxodeoxyguanosine (8-oxo-dG) levels [56]. Urine samples were collected from healthy employees in a steel-manufacturing company, after obtaining informed consent. The mean level of urinary 8-oxo-dG ( $\mu \mathrm{g} / \mathrm{g}$ creatinine) in the 361 male subjects was $4.20 \pm 1.47$ (Table 1). The relationships between 16 categorical lifestyle factors and urinary 8-oxo-dG levels were analyzed by ANOVA. The results revealed that the urinary 8-oxo-dG level was significantly negatively related to fruit consumption $(P=0.03)$ and physical activity $(P=0.03)$. It is noteworthy that, in terms of fruit consumption, the urinary 8-oxo-dG levels of the "rarely" and "two or three times per week" groups were significantly higher than those of the "everyday" group $(P=0.03)$. The results of the Scheffe's test also indicated that fruit consumption significantly reduced the urinary 8-oxo$\mathrm{dG}$ level. Besides urinary analyses, a diet rich in fruit and vegetables was also reportedly effective in the reduction of oxidative stresses [57]. These data indicated that fruit consumption and physical activity reduce oxidative stress generation.

\begin{tabular}{llllll}
\hline variables & category & $\mathbf{n}$ & $\mathbf{0}$ & urinary 8-oxo-dG & $P$ \\
\hline sleep & deficient & 10 & 2.8 & $4.37 \pm 0.25$ & 0.53 \\
& slightly deficient & 181 & 50.1 & $4.19 \pm 0.12$ & \\
sufficient & 170 & 47.1 & $4.20 \pm 0.11$ & \\
holiday & little or none & 2 & 0.6 & $5.41 \pm 1.20$ & 1.00 \\
& once a week & 51 & 14.1 & $3.96 \pm 0.21$ & \\
twice a week & 308 & 85.3 & $4.23 \pm 0.08$ & \\
fatigue & always & 18 & 5.0 & $3.66 \pm 0.32$ & 0.86 \\
& sometimes & 256 & 70.9 & $4.17 \pm 0.09$ & \\
rhythm & rarely & 87 & 24.1 & $4.39 \pm 0.17$ & \\
& irregular & 66 & 18.3 & $4.05 \pm 0.19$ & 0.25 \\
refreshing & mostly regular & 215 & 59.6 & $4.20 \pm 0.10$ & \\
& regular & 80 & 22.2 & $4.30 \pm 0.16$ & \\
size of a meal & difficult & 13 & 3.6 & $4.40 \pm 0.38$ & 0.48 \\
& moderate & 255 & 70.6 & $4.13 \pm 0.09$ & \\
& easy & 93 & 25.8 & $4.33 \pm 0.17$ & \\
& full stomach every time & 24 & 6.6 & $3.87 \pm 0.27$ & 0.85 \\
& no pattern & 198 & 54.8 & $4.29 \pm 0.11$ & \\
& moderation every time & 139 & 38.5 & $4.12 \pm 0.11$ &
\end{tabular}




\begin{tabular}{llllll}
\hline variables & category & n & \% & urinary 8-oxo-dG & $P$ \\
\hline healthy meal & rarely & 46 & 12.7 & $4.25 \pm 0.20$ & 0.11 \\
combination & consider sometimes & 187 & 51.8 & $4.33 \pm 0.12$ & \\
skipping meals & consider every time & 128 & 35.5 & $3.99 \pm 0.11$ & \\
& one meal every day & 63 & 17.5 & $4.37 \pm 0.20$ & 0.62 \\
light-colored vegetable & 2 or 3 meals a week & 103 & 28.5 & $4.09 \pm 0.15$ & \\
& rarely & 195 & 54.0 & $4.20 \pm 0.10$ & \\
& rarely & 17 & 4.7 & $4.32 \pm 0.42$ & 0.78 \\
green- and yellow- & once a day & 268 & 74.2 & $4.22 \pm 0.09$ & \\
colored vegetables & each meal & 76 & 21.1 & $4.09 \pm 0.14$ & \\
& rarely & 26 & 7.2 & $4.10 \pm 0.32$ & 0.75 \\
fruit & 2 or 3 times a week & 244 & 67.6 & $4.21 \pm 0.10$ & \\
& everyday & 91 & 25.2 & $4.18 \pm 0.12$ & \\
meat, fish, egg, etc. & rarely & 140 & 38.8 & $4.24 \pm 0.12$ & 0.03 \\
& 2 or 3 times a week & 187 & 51.8 & $4.28 \pm 0.11$ & \\
milk & everyday & 34 & 9.4 & $3.57 \pm 0.19$ & \\
& rarely & 11 & 3.0 & $4.72 \pm 0.49$ & 0.16 \\
& twice a day & 194 & 53.7 & $4.25 \pm 0.11$ & \\
oil & each meal & 156 & 43.2 & $4.09 \pm 0.11$ & \\
& rarely & 118 & 32.7 & $4.32 \pm 0.16$ & 0.23 \\
2 or 3 times a week & 171 & 47.4 & $4.10 \pm 0.10$ & \\
seaweed & everyday & 72 & 19.9 & $4.23 \pm 0.15$ & \\
& rarely & 9 & 2.5 & $4.41 \pm 0.58$ & 0.55 \\
& 2 or 3 times a week & 192 & 53.2 & $4.15 \pm 0.12$ & \\
& everyday & 160 & 44.3 & $4.24 \pm 0.10$ & \\
& rarely & 58 & 16.1 & $3.99 \pm 0.18$ & 0.75 \\
& 2 or 3 times a week & 266 & 73.7 & $4.26 \pm 0.09$ & \\
& everyday & 37 & 10.2 & $4.04 \pm 0.21$ & \\
& light & 192 & 53.2 & $4.39 \pm 0.11$ & 0.03 \\
& moderate & 119 & 33.0 & $4.09 \pm 0.12$ & \\
& moderately heavy & 12 & 3.3 & $3.85 \pm 0.48$ & \\
& heavy & 38 & 10.5 & $3.68 \pm 0.19$ & \\
& & & & & \\
& & &
\end{tabular}

$P$ : One-way analysis of variance

Urinary 8-oxo-dG data are expressed as $\mu \mathrm{g} / \mathrm{g}$ creatinine $\pm \mathrm{SE}$

These data are derived from a report by Tamae et al. [56] with permission from Wiley-Blackwell.

Table 1. The characteristics of categorical lifestyle factors and urinary 8-oxo-dG levels in 361 male subjects

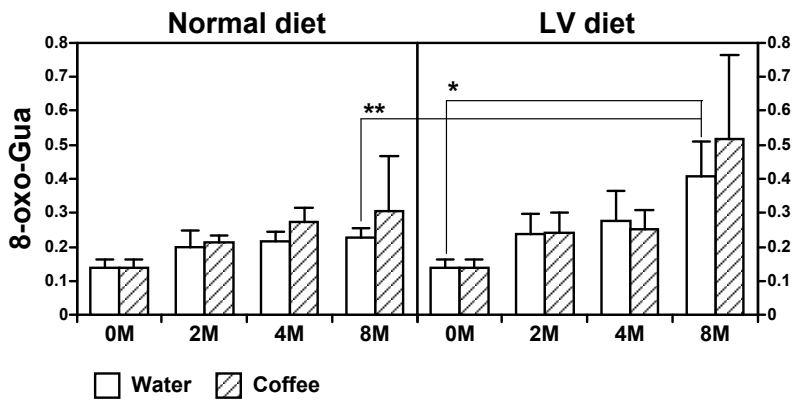

A 


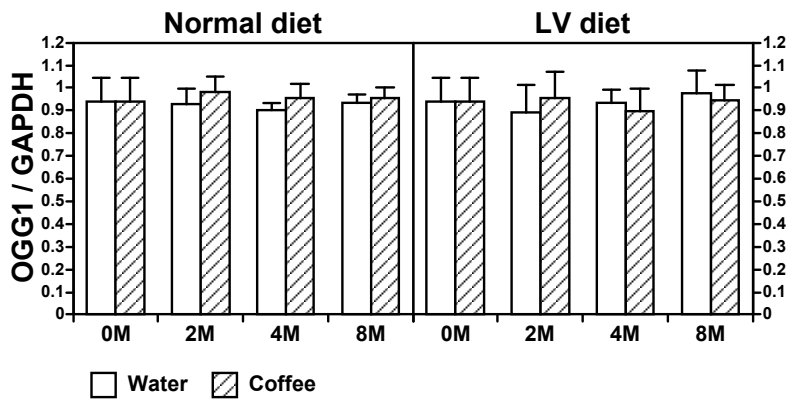

B

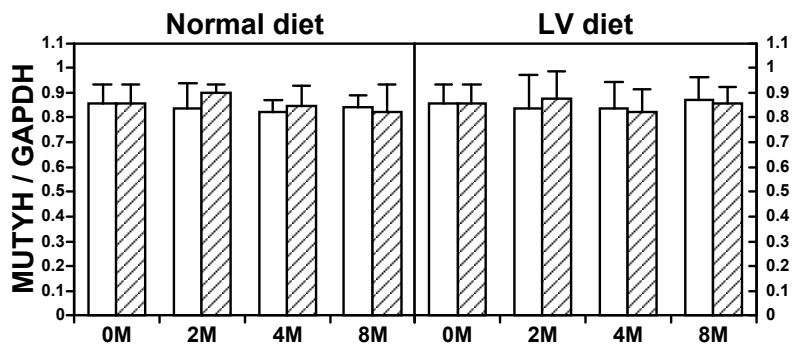

Water $\square$ Coffee

C

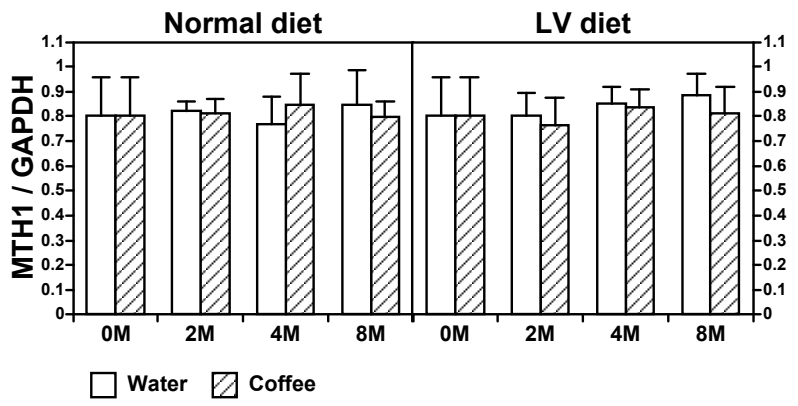

$\mathrm{D}$

Fig. 3. (A) The 8-oxo-dG level in mouse liver DNA. The 8-oxo-dG value is expressed as the number per $10^{5}$ deoxyguanosine. $\mathrm{n}=3$ for data of 4 and 8 months, $\mathrm{n}=4$ for data of 2 months. (B) Ogg1 gene expression level. $\mathrm{n}=4$ for LV diet + water for 8 months, $\mathrm{n}=5$ for others. (C) MUTYH gene expression level. $\mathrm{n}=4$ for LV diet + water for 8 months, $\mathrm{n}=5$ for others. (D) MTH1 gene expression level. $\mathrm{n}=4$ for LV diet + water for 8 months, $\mathrm{n}=5$ for others. The GAPDH gene was used as an internal standard. The total value of the gene expression level was calculated by the ratio of the expression of each gene to GAPDH expression. The values are mean $+\mathrm{SD}$. ${ }^{*} \mathrm{P}<0.005,{ }^{* *} \mathrm{P}<0.05$. LV diet: low vitamin diet. MUTYH: eukaryotic homologue of MutY (mismatched adenine DNA glycosylase), MTH1: eukaryotic homologue of MutT (8-oxo-dGTPase). This figure was published in reference [53], Copyright Blackwell Publishing (license\#: 2634430504476). 


\section{Dietary factors and OGG1 polymorphism}

Interestingly, Sørensen et al. reported that the effect of vegetable consumption was associated with the OGG1 Ser326Cys polymorphism [58]. A non-synonymous (associated with an amino acid change) genetic polymorphism at codon 326, Ser326Cys, in the OGG1 gene is a strong candidate as a genetic factor for cancer risk [59,60]. In fact, the OGG1 Ser326Cys enzyme exhibited functional defects [61]. OGG1 Ser326Cys excised 8-oxo-Gua from duplex DNA and cleaved abasic sites at rates 2- to 6-fold lower than those of the wildtype enzyme. Yamane et al. reported that 8-oxo-Gua-induced mutations were more efficiently suppressed in OGG1-Ser326 transduced cells than OGG1-Cys326 transduced cells, suggesting that OGG1-Cys326 has reduced ability to prevent mutagenesis by 8-oxoGua than OGG1-Ser326 in vivo in human cells [62]. Sørensen et al. observed a 54\% decrease in lung cancer risk per 50\% increase in vegetable intake among homozygous Cys326Cys carriers, and no decrease in risk among carriers of Ser326Ser or Ser326Cys. Therefore, to evaluate the effect of food factors on carcinogenesis, the OGG1 polymorphism should be considered.

\section{Conclusions}

As described above, dietary factors influence 8-oxo-Gua generation and its repair systems in a variety of manners. They may contribute to human diseases, including cancer, by causing DNA damage and affecting DNA repair systems. The effects of food factors on the generation of 8-oxo-Gua and the expression of OGG1 must be further clarified, to reduce the risk of food factor-related diseases, such as cancer or diabetes.

In addition, DNA double-strand break (DAB) is also a well-known DNA damage. Datta et al. reported that 8-oxo-formation was associated with 125 I-induced double-strand break (DSB) formation. Therefore, analyses of food factors and DSB formation should be interested as a further study [63].

\section{Acknowledgements}

The authors thank INTECH OPEN ACCESS PUBLISHER, for inviting us to write this review article, and Elsevier LTD, Blackwell Publishing, and Wiley-Blackwell, for permission to reproduce the material in references [37], [53], and [56], respectively.

\section{References}

[1] K.C. Cheng, D.S. Cahill, H. Kasai, S. Nishimura, and L.A. Loeb, "8-Hydroxyguanine, an abundant form of oxidative DNA damage, causes G-T and A-C substitutions," Journal of Biological Chemistry, vol. 267, pp. 166-172, 1992.

[2] T. Tsuzuki, Y. Nakatsu, and Y. Nakabeppu, "Significance of error-avoiding mechanisms for oxidative DNA damage in carcinogenesis," Cancer Sciences, vol. 98, pp. 465-470, 2007.

[3] L.J. Marnett, “Oxyradicals and DNA damage," Carcinogenesis, vol. 21, pp. 361-370, 2000. 
[4] R.A. Floyd, J.J. Watson, P.K. Wong, D.H. Altmiller, and R.C. Rickard, “Hydroxyl free radical adduct of deoxyguanosine: sensitive detection and mechanisms of formation," Free Radical Research Communications, vol. 1, pp. 163-172, 1986.

[5] Y.J. Wang, Y.S. Ho, M.J. Lo, and J.K. Lin, “Oxidative modification of DNA bases in rat liver and lung during chemical carcinogenesis and aging," Chemico-Biological Interactions, vol. 94, 135-145, 1995.

[6] P. Jaruga, and M. Dizdaroglu, "Repair of products of oxidative DNA base damage in human cells," Nucleic Acids Research, vol. 24, pp. 1389-1394, 1996.

[7] H. Kamiya, N. Murata-Kamiya, S. Koizume, H. Inoue, S. Nishimura, and E. Ohtsuka, “8Hydroxyguanine (7, 8-dihydro-8-oxoguanine) in hot spots of the c-Ha-ras gene: effects of sequence contexts on mutation spectra," Carcinogenesis, vol. 16, pp. 883889, 1995.

[8] H. Kamiya, H. Miura, N. Murata-Kamiya, H. Ishikawa, T. Sakaguchi, H. Inoue, T. Sasaki, C. Masutani, F. Hanaoka, S. Nishimura, and E. Ohtsuka, "8Hydroxyadenine (7, 8-dihydro-8-oxoadenine) induces misincorporation in in vitro DNA synthesis and mutations in NIH 3T3 cells," Nucleic Acids Research, vol. 23, pp. 2893-2899, 1995.

[9] S. Boiteux, T.R. O'Connor, F. Lederer, A. Gouyette, and J. Laval, "Homogeneous Escherichia coli FPG protein," Journal of Biological Chemistry, vol. 265, pp. 3916-3922, 1990.

[10] J. Tchou, H. Kasai, S. Shibutani, M.H. Chung, J. Laval, A.P. Grollman, and S. Nishimura, "8-Oxoguanine (8-hydroxyguanine) DNA glycosylase and its substrate specificity," Proceedings of the National Academy of Sciences of the United States of America, vol. 88, pp. 4690-4694, 1991.

[11] S. Boiteux, E. Gajewski, J. Laval, and M. Dizdaroglu, "Substrate specificity of the Escherichia coli Fpg protein (formamidopyrimidine-DNA glycosylase): excision of purine lesions in DNA produced by ionizing radiation or photosensitization," Biochemistry, vol. 31, pp. 106-110, 1992.

[12] M. Bhagwat, and J.A. Gerlt, “3'- and 5'-strand cleavage reactions catalyzed by the Fpg protein from Escherichia coli occur via successive beta- and delta-elimination mechanisms, respectively," Biochemistry, vol. 35, pp. 659-665, 1996.

[13] P.A. van der Kemp, D. Thomas, R. Barbey, R. De Oliveira, and S. Boiteux, "Cloning and expression in Escherichia coli of the OGG1 gene of Saccharomyces cerevisiae, which codes for a DNA glycosylase that excises 7,8-dihydro-8-oxoguanine and 2,6-diamino-4-hydroxy-5-N-methylformamidopyrimidine," Proceedings of the National Academy of Sciences of the United States of America, vol. 93, pp. 51975202, 1996.

[14] H.M. Nash, S.D. Bruner, O.D. Schärer, T. Kawate, T.A. Addona, E. Sponner, W.S. Lane, and G.I. Verdine, "Cloning of a yeast 8-oxoguanine DNA glycosylase reveals the existence of a base-excision DNA-repair protein superfamily," Current Biology, vol. 6, pp. 968-980, 1996. 
[15] R. Lu, H.M. Nash, and G.L. Verdine, "A mammalian DNA repair enzyme that excises oxidatively damaged guanines maps to a locus frequently lost in lung cancer," Current Biology, vol. 7, pp. 397-407, 1997.

[16] T.A. Rosenquist, D.O. Zharkov, and A.P. Grollman, "Cloning and characterization of a mammalian 8-oxoguanine DNA glycosylase," Proceedings of the National Academy of Sciences of the United States of America, vol. 94, pp. 7429-7434, 1997.

[17] T. Roldán-Arjona, Y.F. Wei, K.C. Carter, A. Klungland, C. Anselmino, R.P. Wang, M. Augustus, and T. Lindahl, "Molecular cloning and functional expression of a human cDNA encoding the antimutator enzyme 8-hydroxyguanine-DNA glycosylase," Proceedings of the National Academy of Sciences of the United States of America, vol. 94, pp. 8016-8020, 1997.

[18] J.P. Radicella, C. Dherin, C. Desmaze, M.S. Fox, and S. Boiteux, "Cloning and characterization of hOGG1, a human homolog of the OGG1 gene of Saccharomyces cerevisiae," Proceedings of the National Academy of Sciences of the United States of America, vol. 94, pp. 8010-8015, 1997.

[19] M. Bjoräs, L. Luna, B. Johnson, E. Hoff, T. Haug, T. Rongnes, and E. Seeberg, “Opposite base-dependent reactions of a human base excision repair enzyme on DNA containing 7, 8-dihydro-8-oxoguanine and abasic sites," The EMBO Journal, vol. 16, pp. 6314-6322, 1997.

[20] K, Arai, K. Morishita, K. Shinmura, T. Kohno, S.R. Kim, T. Nohmi, M. Taniwaki, S. Ohwada, and J. Yokota, "Cloning of a human homolog of the yeast OGG1 gene that is involved in the repair of oxidative DNA damage," Oncogene, vol. 14, pp. 28572861, 1997.

[21] H. Aburatani, Y. Hippo, T. Ishida, R. Takashima, C. Matsuba, T. Kodama, M. Takao, A. Yasui, K. Yamamoto, M. Asano, K. Fukasawa, T. Yoshinari, H. Inoue, E. Ohtsuka, and S. Nishimura, "Cloning and characterization of mammalian 8hydroxyguanine-specific DNA glycosylase/apurinic, apyrimidinic lyase, a functional mutM homologue," Cancer Research, vol. 57, pp. 2151-2156, 1997.

[22] T. Hirano, K. Higashi, A. Sakai, Y. Tsurudome, Y. Ootsuyama, R. Kido, and H. Kasai, "Analyses of oxidative DNA damage and its repair activity in the livers of 3'methyl-4-dimethylaminoazobenzene-treated rodents," Japanese Journal of Cancer Research, vol. 91, pp. 681-695, 2000.

[23] S.A. Smith-Warner, D. Spiegelman, S.S. Yaun, P.A. van den Brandt, A.R. Folsom, A. Goldbohm, S. Graham, L. Holmberg, G.R. Howe, J.R. Marshall, A.B. Miller, J.D. Potter, F.E. Speizer, W.C. Willett, A. Wolk, and D.J. Hunter, "Alcohol and breast cancer in women; A pooled analysis of cohort studies," JAMA, vol. 279, pp.535-540, 1998.

[24] R.Z. Stolzenberg-Solomon, S.C. Chang, M.F. Leitzmann, K.A. Johnson, C. Johnson, S.S. Buys, R.N. Hoover, and R.G. Ziegler, "Folate intake, alcohol use, and postmenopausal breast cancer risk in the prostate, lung, colorectal, and ovarian cancer screening trial," The American Journal of Clinical Nutrition, vol. 83, pp. 895904, 2006. 
[25] M. Wu, J.K. Zhao, X.S. Hu, P.H. Wang, Y. Qin, Y.C. Lu, J. Yang, A.M. Liu, D.L. Wu, Z.F. Zhang, K.J. Frans, and P. van't Veer, “Association of smoking, alcohol drinking and dietary factors with esophageal cancer in high- and low-risk areas of Jiangsu Province, China," World Journal of Gastroenterology, vol. 12, pp. 16861693, 2006.

[26] A.L. Klatsky, M.A. Armstrong, and G.D.Friedman, "The relations of alcoholic beverage use to colon and rectal cancer," American Journal of Epidemiology, vol. 128, pp. 10071015, 1988.

[27] J. Ho, T. Lam, and L. Chiu, "Smoking, drinking and colorectal cancer in Hong Kong Chinese: A case control study," International Journal of Cancer, vol. 109, pp. 587-597, 2004.

[28] J.C. Anderson, Z. Alpern, G. Sethi, C.R. Messina, C. Martin, P.M. Hubbard, R. Grimson, P.F. Ells, and R.D. Shaw, "Prevalence and risk of colorectal neoplasia in consumers of alcohol in a screening population," The American Journal of Gastroenterology, vol. 100, pp. 2049-2055, 2005.

[29] P.M. Webb, D.M. Purdie, C.J. Bain, and A.C. Green, "Alcohol, wine, and risk of epithelial ovarian cancer," Cancer Epidemiology, Biomarkers, and Prevention, vol. 13, pp. 592-599, 2004.

[30] N.C. Briggs, R.S. Levine, L.D. Bobo, W.P. Haliburton, E.A. Brann, and C.H. Hennekens, "Wine drinking and risk of non-Hodgkin's lymphoma among men in the United States: A population-based case-control study," American Journal of Epidemiology, vol. 156, pp. 454-462, 2002.

[31] S. Dragoni, J. Gee, R. Bennett, M. Valoti, and G. Sgaragli, "Red wine alcohol promotes quercetin absorption and directs its metabolism towards isorhamnetin and tamarixetin in rat intestine in vitro," British Journal of Pharmacology, vol. 147, pp. 765771, 2006.

[32] Y. Wang, K.W. Lee, F.L. Chan, S. Chen, and L.K. Leung, "The red wine polyphenol resveratrol displays bilevel inhibition on aromatase in breast cancer cells," Toxicological Sciences, vol. 92, pp. 71-77, 2006.

[33] S. Mahabir, M.F. Leitzmann, M.J. Virtanen, J. Virtamo, P. Pietinen, D. Albanes, and P.R. Taylor, "Prospective study of alcohol drinking and renal cell cancer risk in a cohort of Finnish male smokers," Cancer Epidemiology, Biomarkers, and Prevention, vol. 14, pp. 170-175, 2005.

[34] S. Petti and C. Scully, "Association between different alcoholic beverages and leukoplakia among non- to moderate-drinking adults: A matched case-control study," European Journal of Cancer, vol. 42, pp. 521-527, 2006.

[35] B.M. Arendt, S. Ellinger, K. Kekic, L. Geus, R. Fimmers, U. Spengler, W.U. Müller, and R. Goerich, "Single and repeated moderate consumption of native or dealcoholized red wine show different effects on antioxidant parameters in blood and DNA strand breaks in peripheral leukocytes in healthy volunteers: a randomized controlled trial (ISRCTN68505294)," Nutrition Journal, vol. 14, p. 33, 2005.

[36] R.A.A. Caccetta, V. Burke, V.B. Mori, L.J. Beilin, I.B. Puddey, and K.D. Croft, “Red wine polyphenols, in the absence of alcohol, reduce lipid peroxidative stress 
in smoking subjects," Free Radical and Biological Medicine, vol. 30, pp. 636-642, 2001.

[37] T. Hirano, A. Sakai, Y. Ootsuyama, and H. Kasai, "Chronic alcohol consumption prevents 8-hydroxyguanine accumulation in 3'-methyl-4dimethylaminoazobenzene-treated mouse liver," Biochemical and Biophysical Research Communications, vol. 387, pp. 316-320, 2009.

[38] T. Hirano, Y. Yamaguchi, H. Hirano, and H. Kasai, "8-Hydroxyguanine levels in nuclear DNA and its repair activity in rat organs associated with age," Journal of Gerontology, vol. 51A, pp. B303-B307, 1996.

[39] T.K. Hazra, J.W. Hill, T. Izumi, and S. Mitra, "Multiple DNA glycosylases for repair of 8-oxoguanine and their potential in vivo functions," Progress in Nucleic Acid Research and Molecular Biology, vol. 68, pp. 193-205, 2001.

[40] G.B. Keijzers, C.J. Tack, B.E. De Galan, and P. Smits, "Caffeine can decrease insulin sensitivity in humans," Diabetes Care, vol. 25, pp. 364-369, 2002.

[41] H. Iso, C. Date, K. Wakai, M. Fukui, A. Tamakoshi, and the JACC Study Group, "The relationship between green tea and total caffeine intake and risk for self-reported type 2 diabetes among Japanese adults," Annals of Internal Medicine, vol. 144, pp. 554-562, 2006.

[42] S. Gallus, M. Bertuzzi, A. Tavani, C. Bosetti, E. Negri, C.L. Vecchia, P. Lagiou, and D. Trichopoulos, "Does coffee protect against hepatocellular carcinoma?," British Journal of Cancer, vol. 87, pp. 956-959, 2002.

[43] Y. Kurozawa, I. Ogimoto, A. Shibata, T. Nose, T. Yoshimura, H. Suzuki, R. Sakata, Y. Fujita, S. Ichikawa, N. Iwai, and A. Tamakoshi, "Coffee and risk of death from hepatocellular carcinoma in a large cohort study in Japan," British Journal of Cancer, vol. 93, pp. 607-610, 2005.

[44] S.R. Brown, P.A. Cann, and N.W. Read, "Effect of coffee on distal colon function," Gut, vol. 31, pp. 450-453, 1990.

[45] K.J. Lee, M. Inoue, T. Otani, M. Iwasaki, S. Sasazuki, S. Tsugami, and the JPHC Study Group, "Coffee consumption and risk of colorectal cancer in a population-based prospective cohort of Japanese men and women," International Journal of Cancer, vol. 121, pp. 1312-1318, 2007.

[46] A. Nehlig and G. Debry, "Potential genotoxic, mutagenic and antimutagenic effects of coffee: a review," Mutation Research, vol. 317, pp. 145-162, 1994.

[47] S.C. Larsson, L. Bergkvist, E. Giovannucci, and A. Wolk, "Coffee consumption and incidence of colorectal cancer in two prospective cohort studies of Swedish women and men," American Journal of Epidemiology, vol. 163, pp. 638-644, 2006.

[48] T. Naganuma, S. Kuriyama, M. Akhter, M. Kakizaki, N. Nakaya, K. Matsuda-Ohmori, T. Shimazu, A. Fukao, and I. Tsuji, "Coffee consumption and the risk of colorectal cancer: a prospective cohort study in Japan," International Journal of Cancer, vol. 120, pp. 1542-1547, 2007.

[49] M. Nagao, Y. Fujita, K. Wakabayashi, H. Nukaya, T. Kosuge, and T. Sugimura, "Mutagens in coffee and other beverages," Environmental Health Perspectives, vol. 67, pp. 89-91, 1986. 
[50] B.N. Ames and E.S. Gold, "Environmental pollution, pesticide, and the prevention of cancer: misconceptions," The FASEB Journal, vol. 11, pp. 1041-1052, 1997.

[51] S.C. Larsson, E. Giovannucci, and A. Wolk, "Coffee consumption and stomach cancer risk in a cohort of Swedish women," International Journal of Cancer, vol. 119, pp. 2186-2189, 2006.

[52] M. Akagawa, T. Shigemitsu, and K. Suyama, "Production of hydrogen peroxide by polyphenols and polyphenol-rich beverages under quasi-physiological conditions," Bioscience, Biotechnology, and Biochemistry, vol. 67, pp. 26322640, 2003.

[53] H. Morii, A. Kuboyama, T. Nakashima, K. Kawai, H. Kasai, K. Tamae, and T. Hirano, "Effects of instant coffee consumption on oxidative DNA damage, DNA repair, and redox system in mouse liver," Journal of Food Sciences, vol. 74, pp. H155-H161, 2009.

[54] N. Yoshioka, H. Nakashima, K. Hosoda, Y. Eitaki, N. Shimada, and K. Omae, “Urinary excretion of an oxidative stress marker, 8-hydroxyguanine (8-OH-Gua), among nickel-cadmium battery workers," Journal of Occupational Health, vol. 50, 229-235, 2008.

[55] M.C. Cooke, P.T. Henderson, and M.D. Evans, "Sources of extracellular, oxidativelymodified DNA lesions: implications for their measurement in urine," Journal of Clinical Biochemistry and Nutrition, vol. 45, pp. 255-270, 2009.

[56] K. Tamae, K. Kawai, S. Yamasaki, K. Kawanami, M. Ikeda, K. Takahashi, T. Miyamoto, N. Kato, and H. Kasai, "Effect of age, smoking and other lifestyle factors on urinary 7-methylguanine and 8-hydroxydeoxyguanosine," Cancer Sciences, vol. 100, pp. 715-721, 2009.

[57] S. Guarrera, C. Sacerdote, L. Fiorini, R. Marsala, S. Polidoro, S. Gamberini, F. Saletta, C. Malaveille, G. Talaska, P. Vineis, and G. Matullo, “Expression of DNA repair and metabolic genes in response to a flavonoid-rich diet," British Journal of Nutrition, vol. 98, pp. 525-533, 2007.

[58] M. Sørensen, O. Raaschou-Nielsen, R.D. Hansen, A. Tjønneland, K. Overvad, and U. Vogel, "Interaction between the OGG1 Ser326Cys polymorphism and intake of fruit and vegetables in relation to lung cancer," Free Radical Research, vol. 40, pp. 885-891, 2006.

[59] T. Kohno, K. Shinmura, M. Tosaka, M. Tani, S.R. Kim, H. Sugimura, T. Nohmi, H. Kasai, and J. Yokota, "Genetic polymorphisms and alternative splicing of the hOGG1 gene, that is involved in the repair of 8-hydroxyguanine in damaged DNA," Oncogene, vol. 16, pp. 3219-3225, 1998.

[60] C. Dherin, J.P. Radicella, M. Dizdaroglu, and S. Boiteux, "Excision of oxidatively damaged DNA bases by the human alpha-hOgg1 protein and the polymorphic alpha-hOgg1 (Ser326Cys) protein which is frequently found in human populations," Nucleic Acids Research, vol. 27, pp. 4001-4007, 1999.

[61] J.W. Hill and M. Evans, "Dimerization and opposite base-dependent catalytic impairment of polymorphic S326C OGG1 glycosylase," Nucleic Acids Research, vol. 34, pp. 1620-1632, 2006. 
[62] A. Yamane, T. Kohno, K. Ito, N. Sunaga, K. Aoki, K. Yoshimura, H. Murakami, Y. Nojima, and J. Yokota, "Differential ability of polymorphic OGG1 proteins to suppress mutagenesis induced by 8-hydroxyguanine in human cell in vivo," Carcinogenesis, vol. 25, pp. 1689-1694, 2004.

[63] K. Datta, P. Jaruga, M. Dizdaroglu, R.D. Neumann, and T.A. Winters, “Molecular analysis of base damage clustering associated with a site-specific radiation-induced DNA double-strand break," Radiation Research, vol. 166, pp. 767-781, 2006. 


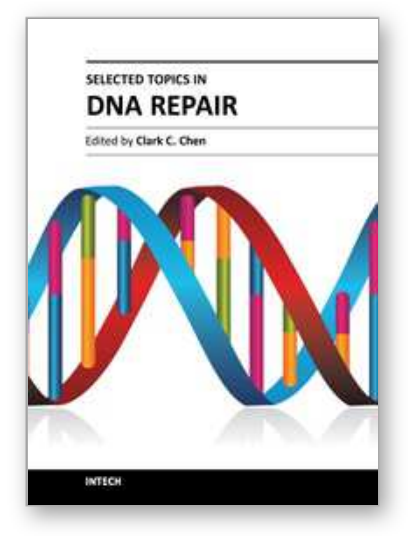

\author{
Selected Topics in DNA Repair \\ Edited by Prof. Clark Chen
}

ISBN 978-953-307-606-5

Hard cover, 572 pages

Publisher InTech

Published online 26, October, 2011

Published in print edition October, 2011

This book is intended for students and scientists working in the field of DNA repair, focusing on a number of topics ranging from DNA damaging agents and mechanistic insights to methods in DNA repair and insights into therapeutic strategies. These topics demonstrate how scientific ideas are developed, tested, dialogued, and matured as it is meant to discuss key concepts in DNA repair. The book should serve as a supplementary text in courses and seminars as well as a general reference for biologists with an interest in DNA repair.

\title{
How to reference
}

In order to correctly reference this scholarly work, feel free to copy and paste the following:

Takeshi Hirano and Kazuyoshi Tamae (2011). Food Factors and Oxidative DNA Damage / DNA Repair Systems, Selected Topics in DNA Repair, Prof. Clark Chen (Ed.), ISBN: 978-953-307-606-5, InTech, Available from: http://www.intechopen.com/books/selected-topics-in-dna-repair/food-factors-and-oxidative-dna-damagedna-repair-systems

\section{INTECH}

open science | open minds

\author{
InTech Europe \\ University Campus STeP Ri \\ Slavka Krautzeka 83/A \\ 51000 Rijeka, Croatia \\ Phone: +385 (51) 770447 \\ Fax: +385 (51) 686166 \\ www.intechopen.com
}

\author{
InTech China \\ Unit 405, Office Block, Hotel Equatorial Shanghai \\ No.65, Yan An Road (West), Shanghai, 200040, China \\ 中国上海市延安西路65号上海国际贵都大饭店办公楼 405 单元 \\ Phone: +86-21-62489820 \\ Fax: +86-21-62489821
}


(C) 2011 The Author(s). Licensee IntechOpen. This is an open access article distributed under the terms of the Creative Commons Attribution 3.0 License, which permits unrestricted use, distribution, and reproduction in any medium, provided the original work is properly cited. 